\title{
Processo de internacionalização das empresas brasileiras do segmento de segurança e defesa
}

Renato Santiago Quintal
Mestrado em Ciências Contábeis pela Universidade do Estado do Rio de Janeiro -

UERJ

Rua São Francisco Xavier, 524. Maracanã. Rio de Janeiro/RJ. CEP: 20550-900

E-mail: rsantiago79@hotmail.com

Robson Augusto Dainez Condé

Mestrado em Ciências Contábeis pela Universidade do Estado do Rio de Janeiro -

UERJ

Rua São Francisco Xavier, 524. Maracanã. Rio de Janeiro/RJ. CEP: 20550-900

E-mail: robsonconde.mcc.uerj@hotmail.com

Leonardo Portugal Barcellos

Mestrado em Ciências Contábeis pela Universidade do Estado do Rio de Janeiro -

UERJ

Rua São Francisco Xavier, 524. Maracanã. Rio de Janeiro/RJ. CEP: 20550-900.

E-mail: Ipbarcellos@gmail.com

Josir Simeone Gomes

Mestrado em Administração pela Universidade do Grande Rio - UNIGRANRIO Rua Professor José de Souza Herdy, 1160. Jardim Vinte e Cinco de Agosto. Duque de

Caxias/RJ. CEP: 25071-202

E-mail: josirgomes@superig.com.br

\section{RESUMO}

O presente estudo teve por objetivo investigar o processo de internacionalização das empresas que compõem o segmento de segurança e defesa, bem como analisar os impactos decorrentes desse processo em seus sistemas de controle de gestão. Um questionário não estruturado foi submetido a todas as empresas filiadas à Associação Brasileira das Indústrias de Materiais de Defesa e Segurança, buscando coletar as informações necessárias à análise. Foram entrevistados executivos de dezenove empresas, em dezembro de 2011, e utilizada a análise de conteúdo para o tratamento das respostas. Dos resultados obtidos, verificou-se que a internacionalização provocou modificações significativas na estrutura organizacional e nos sistemas de controle gerencial das empresas, com a introdução de novos artefatos de controle, com vistas ao aperfeiçoamento do processo de tomada de decisão.

Palavras-chave: Internacionalização. Controle Gerencial. Indústria de Defesa. Forças Armadas. 
Processo de internacionalização das empresas brasileiras do segmento de segurança e defesa

Renato Santiago Quintal, Robson Augusto Dainez Condé, Leonardo Portugal Barcellos, Josir Simeone

Gomes

\section{Process of internationalization of brazilian companies in the segment of security and defence}

\section{ABSTRACT}

The present study aimed to investigate the process of internationalization of companies that comprise the segment of security and defense, as well as analyze the impacts arising from that process in their management control systems. A unstructured questionnaire was submitted to all companies affiliated to the Brazilian Defense and Security Industries Association, aiming to gather the information necessary to analyze. Nineteen companies executives were interviewed in December 2011, and used content analysis for the treatment of answers. Of the results obtained, it was found that caused significant changes in the organizational structure and internationalization of corporate managerial control systems, with the introduction of new control artifacts, with a view to improving the decision-making process.

Keywords: Internationalization. Managerial Control. Defence Industry. Armed Forces.

\section{INTRODUÇÃO}

$\mathrm{Na}$ estrutura produtiva das economias avançadas, a Indústria de Materiais e Serviços de Defesa desponta como um dos segmentos mais importantes, tendo em vista o caráter estratégico que ocupa por estar associada à produção de equipamentos de defesa do país, diretamente ligada ao domínio de tecnologias sensíveis. Também devem ser considerados os aspectos econômicos que estão relacionados à geração de exportações, ao elevado valor adicionado e aos empregos de alta qualificação. Assim, a estruturação e o fortalecimento da Base Industrial de Defesa (BID) passam a ser fundamentais para um país como o Brasil que, além de possuir um invejável patrimônio de recursos humanos e naturais, busca a inserção cada vez mais ativa no cenário político e econômico internacional (ABDI, 2011).

É inegável a contribuição desse segmento ao parque industrial de um país, já que grande parte das inovações tecnológicas em produtos, processos ou serviços surgem a partir de pesquisas destinadas ao atendimento das necessidades militares. Através de um processo de spin off da tecnologia gerada, esse conhecimento é 
Processo de internacionalização das empresas brasileiras do segmento de segurança e defesa

Renato Santiago Quintal, Robson Augusto Dainez Condé, Leonardo Portugal Barcellos, Josir Simeone

capilarizado ao setor civil, através da produção de bens e prestação de serviços. A Internet e o GPS (iniciais de Global Position System) são exemplos emblemáticos dessa possibilidade (LONGO, 2007).

De acordo com a Associação Brasileira das Indústrias de Materiais de Defesa e Segurança (ABIMDE, 2008), o setor industrial brasileiro é composto por cerca de 300 empresas, das quais apenas 25 são exportadoras. Para o Ministério da Defesa (BRASIL, 2005), a Base Industrial de Defesa (BID) representa o conjunto das empresas estatais e privadas e as organizações civis e militares que participam de uma ou mais das fases de pesquisa, desenvolvimento, produção, distribuição e manutenção de produtos estratégicos de defesa (bens e serviços). Para fins deste estudo, foi realizado um recorte na BID, priorizando-se a análise do conjunto formado pelas 129 empresas filiadas à ABIMDE.

Historicamente, o tema tem sido tratado de forma sigilosa, atribuído apenas à defesa da integridade nacional e de interesse exclusivo das Forças Armadas. Nessa linha, os demais setores da sociedade e da economia estariam alijados do processo produtivo, competindo-Ihes o papel de fornecer insumos de baixo valor agregado (PROENÇA; DINIZ, 1998).

Entretanto, tem surgido uma nova abordagem sobre o assunto, principalmente após a entrada em vigor do Decreto n. 6.703, em 18 de dezembro de 2008, que aprovou a Estratégia Nacional de Defesa (END). Essa nova política visa a reforçar as atividades conjuntas entre entidades de pesquisa das Forças Armadas, academia e o empresariado brasileiro, fomentando a criação de um complexo militar-universitárioempresarial apto a operar na fronteira tecnológica e capaz de permitir utilidade dual, ou seja, civil e militar, que alavanca o retorno dos investimentos realizados (BRASIL, 2008). Nesse novo paradigma, o sistema de defesa possui capacidade para contribuir para a evolução econômica, social, política, científica e tecnológica do país, mas para atender a todos esses anseios as empresas precisam estar aptas a atuar em um ambiente marcado pela forte concorrência, que é a principal característica dos negócios no atual mundo globalizado. 
Processo de internacionalização das empresas brasileiras do segmento de segurança e defesa

Renato Santiago Quintal, Robson Augusto Dainez Condé, Leonardo Portugal Barcellos, Josir Simeone

O nível de abertura desse mundo globalizado faz com que as empresas adotem estratégias voltadas à ampliação de suas atividades no exterior, visando a vantagens como: conquista de novos mercados, acesso a diferentes tecnologias, superação de barreiras protecionistas, proximidade com o cliente, presença em blocos regionais que ampliem sua área de atuação, pulverização dos riscos, expansão de escalas com a redução de custos, obtenção de financiamento em condições mais favoráveis, entre outros (TEIXEIRA, 2006).

Sendo assim, espera-se que as empresas do segmento da BID, uma vez imersas nas diretrizes traçadas pela END, estejam adotando a internacionalização como estratégia de geração de vantagens competitivas. Além disso, uma vez internacionalizadas, espera-se que tais empresas tenham promovido mudanças em seus sistemas de controle de gestão, pois, ao expandir suas atividades além das fronteiras de sua nacionalidade, fazem-se imprescindíveis novas formas de aferir se o planejado foi de fato alcançado. De acordo com Dyment (1987), as empresas podem se estabelecer como nacionais, multinacionais ou globais e podem migrar de um modelo para outro, desde que o sistema de controle gerencial seja modificado para retratar a nova estratégia, necessária às unidades de negócios. Se os controles anteriores forem mantidos, as ações da empresa podem ser desviadas de seu foco, o que pode levar ao fracasso da estratégia expansionista.

Nesse contexto, o presente estudo teve por objetivo investigar o processo de internacionalização das empresas que compõem o segmento de segurança e defesa, bem como analisar os impactos decorrentes desse processo em seus sistemas de controle de gestão.

O trabalho está estruturado em cinco seções, a saber: introdução; revisão de literatura; metodologia; resultados; e considerações finais. 
Processo de internacionalização das empresas brasileiras do segmento de segurança e defesa

Renato Santiago Quintal, Robson Augusto Dainez Condé, Leonardo Portugal Barcellos, Josir Simeone

Gomes

\section{REVISÃO DE LITERATURA}

Esta seção é composta pelas seguintes subseções: breve histórico do setor; internacionalização e controle gerencial; e estudos anteriores dedicados à Base Industrial de Defesa.

\subsection{Breve Histórico do Setor}

Os primeiros passos rumo à formação da Base Industrial de Defesa brasileira foram dados no fim do século XVIII e início do século XIX, com a fundação da Casa do Trem de Artilharia e da Fábrica Real de Pólvora da Lagoa Rodrigo de Freitas, em 1762 e 1808, respectivamente. A partir de então e até a Revolução Militar de 1964, a BID passou por avanços e retrocessos acompanhando os ciclos econômicos atravessados pelo país, tais como a ascensão e o declínio do ciclo do açúcar, seguido pelo ouro e pelo café. Alguns surtos de evolução foram observados em épocas de conflitos armados, como foi o caso da Guerra da Tríplice Aliança (1865-1870), que representou marco importante para a indústria de defesa (CUNHA, 2005).

Apesar desses primeiros movimentos, no início do período Militar, o Brasil contava com uma indústria de defesa bastante defasada, o que, conforme Cunha (2005), ocorreu devido à política nacional que priorizava o Acordo de Assistência Militar Brasil-EUA (1952-1976), privilegiando a importação dos excedentes de guerra (munições, armas e equipamentos) daquele país, compostos quase que totalmente por equipamentos usados e/ou recondicionados.

No entanto, dado que o desenvolvimento da indústria de defesa foi uma das prioridades dos governos do período, quando os militares deixaram o poder, a indústria nacional projetava-se como a mais desenvolvida entre os países do Terceiro Mundo (FRANKO-JONES, 1988). De acordo com Matheus (2010), o desenvolvimento da BID se deu por uma convergência de fatores que foram impulsionados pelo constante incentivo governamental, destacando-se o apoio aos setores de alta tecnologia, que eram valorizados ao atender às demandas da indústria de defesa, além do suporte das 
Processo de internacionalização das empresas brasileiras do segmento de segurança e defesa

Renato Santiago Quintal, Robson Augusto Dainez Condé, Leonardo Portugal Barcellos, Josir Simeone

agências de fomento, como o Banco Nacional do Desenvolvimento Econômico e Social (BNDES) e o Fundo Tecnológico (Funtec).

Adicionalmente, o desenvolvimento da indústria de defesa nacional aconteceu em paralelo ao processo de industrialização, sendo que o fortalecimento da indústria metalmecânica foi importante indutor de todo o processo (STRACHMAN; DEGLIESPOSTI, 2010).

Bastos (2008) acrescenta que o contexto internacional das décadas de 1970 e 1980, marcado pela Guerra Fria e por focos de conflito em diversas partes do planeta, impulsionou o sucesso do empreendimento. A maciça entrada de petrodólares oriundos especialmente da Líbia e do Iraque era a tradução da boa aceitação do produto brasileiro no mercado internacional. Com isso, ao longo dos anos 1980, a indústria de defesa brasileira chegou a alcançar a marca de oitava exportadora mundial nesse segmento.

O fim do regime militar representou um severo golpe para a BID, pois passou a haver divergências entre esta e o Governo, que deu prioridade a projetos como: a aeronave subsônica AMX; o tanque Osório; o Veículo Lançador de Satélites (VLS) e o programa de desenvolvimento de um submarino de propulsão nuclear da Marinha (CONCA, 1992). Desta forma, o cenário global da década de 1990 não mais apresentava condições favoráveis aos produtos brasileiros. O colapso nas exportações dos produtos brasileiros também esteve associado ao término da guerra entre o Irã e o Iraque, ao final da Guerra Fria, bem como à decorrente contração do mercado de armamento. Diante disso, a indústria nacional procedeu a uma drástica redução em seus planos de carga, principalmente sobre aquela voltada para o mercado externo (SCHWAM-BAIRD, 1997).

No contexto atual, o Brasil ocupa, de um lado, a oitava posição no ranking global dos exportadores de produtos de defesa; de outro, a décima quinta posição entre os maiores importadores. Diante desse quadro era de se esperar um saldo positivo em termos de balança comercial, entretanto ocorre o contrário, pois a pauta de exportações é composta por produtos convencionais de média e baixa intensidade tecnológica, 
Processo de internacionalização das empresas brasileiras do segmento de segurança e defesa

Renato Santiago Quintal, Robson Augusto Dainez Condé, Leonardo Portugal Barcellos, Josir Simeone

enquanto as importações são, em sua maioria, de produtos de alta tecnologia e maior valor agregado (ABDI, 2011).

\subsection{Internacionalização e Controle Gerencial}

Entre o fim dos anos 1970 e o início dos anos 1990, quando indústria de defesa brasileira atravessou uma fase próspera seguida pelo severo declínio, o mundo assistia à aceleração do fenômeno da globalização que, entre outros, vem possibilitando que bens e serviços sejam negociados transnacionalmente.

Uma das principais marcas da globalização é a abertura dos mercados aos produtos oriundos dos mais diversos países, o que vem levando a um sensível aumento da concorrência e, consequentemente, impõe às empresas a necessidade de que sejam formuladas novas estratégias e novos arranjos para o estabelecimento de suas metas. Muitas organizações identificaram a estratégia de internacionalização como a melhor forma de auferir vantagem competitiva, bem como diversificar o risco sistemático de seus negócios (GOMES; SALAS, 2001). De acordo com Sotto-Mayor Filho e Ferreira (2006), esse processo pode ser iniciado por meio de:

I. Exportação, que conta com a vantagem de dispensar despesas para o estabelecimento da empresa em outros países, mas que requer, de toda a forma, que sejam criados canais de marketing e distribuição dos seus produtos e serviços;

II. Licenciamento, que é a venda a uma empresa estrangeira do direito de fabricar e vender produtos e serviços em uma determinada região e por um tempo fixado. Normalmente, o licenciador recebe royalties por unidade produzida ou vendida;

III. Alianças estratégicas, que são arranjos cooperativos pelos quais se busca atingir os objetivos organizacionais de forma colaborativa, deixando de lado a competitividade que poderia existir entre as empresas envolvidas;

IV. Aquisições, que costumam requerer altos investimentos, mas, em contrapartida, proporcionam acesso rápido a um novo mercado, o que as torna excelentes alternativas de expansão internacional; e 
Processo de internacionalização das empresas brasileiras do segmento de segurança e defesa Renato Santiago Quintal, Robson Augusto Dainez Condé, Leonardo Portugal Barcellos, Josir Simeone

V. Estabelecimento de uma nova subsidiária, que normalmente é a forma mais complexa e custosa, mas que tem como vantagem o fato de que o modelo de negócio permanece inalterado, permitindo maior controle sob o processo.

Uma vez iniciado o processo de internacionalização, seguindo um dos modelos anteriormente apontados, as empresas bem sucedidas podem se estabelecer como: (i) exportadoras, que são aquelas em que as unidades operacionais permanecem no país de origem; (ii) multinacionais, que exploram suas vantagens competitivas diversificando as atividades em outros países, tendo como objetivo a reprodução quase exata da matriz em cada uma das filiais no exterior; (iii) globais, adotando estratégias coordenadas com todos os países onde opera, de forma que o objetivo é adquirir vantagem competitiva em termos de custos e receitas através de operações centralizadas em escala global; ou (iv) transnacional, que combina eficiência econômica e capacidade de responder a mercados locais à flexibilidade para transmitir as experiências que surgem em alguns países para toda a organização. Há, ainda, a possibilidade de migração de um modelo para outro (BARTLETT; GHOSHAL, 1992; CANALS, 1994; DYMENT, 1987).

Florentino e Gomes (2009), ao abordarem o assunto, trazem a lume o modelo de Uppsala, desenvolvido na universidade que the cedeu o nome, tratando a internacionalização como um ajuste da empresa às condições de seu ambiente, conforme os seguintes estágios (FLORENTINO; GOMES, 2009, p. 29):

Estágio 1 - não existência de atividades regulares de exportação;

Estágio 2 - exportação feita através de representantes independentes;

Estágio 3 - estabelecimento de uma subsidiária de venda no exterior; e

Estágio 4 - unidades de operações no exterior (produção, por exemplo).

Dyment (1987) sugere que, acompanhando as mudanças entre os diferentes modelos ou estágios, o sistema de controle gerencial deve ser modificado de modo a retratar a nova estratégia da unidade de negócios, ressaltando que no caso dos controles anteriores serem mantidos, as ações da empresa podem ser desviadas de seu foco, podendo acarretar o fracasso do processo de internacionalização. 
Processo de internacionalização das empresas brasileiras do segmento de segurança e defesa

Renato Santiago Quintal, Robson Augusto Dainez Condé, Leonardo Portugal Barcellos, Josir Simeone

Neste ponto, antes de prosseguir abordando as mudanças nos sistemas de controle de gestão, importa que seja apresentada a definição destes. Muitos estudos debruçaram-se sobre a definição de controle de gestão, sendo que aquela que melhor se coaduna aos objetivos do presente estudo é a defendida por Gomes e Salas (2001). Esses autores entendem controle como a ferramenta fundamental para assegurar que as atividades de uma empresa se realizem da forma desejada pelos membros da organização, contribuindo para a manutenção e melhoria da posição competitiva, bem como para a consecução das estratégias, planos, programas e operações, consentâneos com as necessidades identificadas pelos clientes.

$\mathrm{Na}$ literatura sobre o tema, há alguma convergência acerca dos fatores que justificam as mudanças nos sistemas de controle sugeridas por Dyment (1987). Entre esses fatores, merecem destaque as diferenças culturais entre os países, pois, embora não afetem diretamente 0 desenho do sistema de controle, podem influenciar significativamente a forma como a informação gerada pelo sistema é usada. Isso decorre da própria natureza humana, visto que pessoas de diferentes origens reagem de formas diversas aos mecanismos de controle gerencial, sempre de acordo com suas preferências, hábitos e costumes, o que evidencia o caráter comportamental do controle (ANTHONY; GOVINDARAJAN, 2002; MERCHANT, 1998; DYMENT, 1987; GOMES; SALAS, 2001; MACIARIELLO; KIRBY, 1994). Afora as questões culturais, surgem aquelas de ordem técnica ou operacional, entre as quais Anthony e Govindarajan (2002) destacam a política de preços de transferência e as taxas de câmbio.

Em operações internacionais, o preço de transferência, entendido como o valor expresso em moeda corrente da movimentação de bens e serviços entre unidades organizacionais de uma mesma empresa, sofre distorções em função de fatores como tributação, regulamentações governamentais, tarifas, controles de divisas, acúmulo de reservas e joint ventures. A dificuldade para a formação de preços de transferências justos pode acarretar vantagem de algumas unidades regionais sobre outras no que diz respeito à apuração dos resultados de cada unidade (ANTHONY; GOVINDARAJAN, 2002; MACIARIELLO; KIRBY, 1994). De modo análogo, as diferentes taxas de câmbio 
Processo de internacionalização das empresas brasileiras do segmento de segurança e defesa

Renato Santiago Quintal, Robson Augusto Dainez Condé, Leonardo Portugal Barcellos, Josir Simeone

afetam os fluxos de caixa, representando graves problemas a empresas internacionalizadas, pois, de igual forma, geram oscilações indesejáveis no grau de desempenho das unidades localizadas em diferentes países (ANTHONY; GOVINDARAJAN, 2002; MERCHANT, 1998).

Merchant (1998) destaca, ainda, os riscos decorrentes do diferente ambiente institucional encontrado nos países nos quais a empresa se instala. É imprescindível conhecer, por exemplo, as características basilares do sistema legal, como direito de propriedade, enforcement para o cumprimento de contratos e relações trabalhistas, além da organização do sistema financeiro e os padrões contábeis vigentes.

Segundo Condé et al. (2011), a literatura defende que empresas multinacionais planejem a utilização de seus recursos com base no sucesso de cada unidade de negócio, necessitando, desta forma, de sistemas descentralizados de controle de gestão. De outro giro, para empresas globalizadas, a avaliação de uma unidade de negócios quanto à relação retorno-investimento em um determinado local pode ser irrelevante, quando considerada a contribuição que este investimento pode trazer para os resultados globais e de longo prazo da organização. Assim, o retorno obtido por uma unidade pode ser negativo e, mesmo assim, novos investimentos podem ser justificados pela contribuição que pode trazer para a estratégia mundial. Portanto, a empresa globalizada deve ter administração centralizada e o resultado local não deve servir, necessariamente, como parâmetro para avaliar o sucesso da organização.

\subsection{Estudos Anteriores Dedicados à Base Industrial de Defesa}

Além dos aspectos históricos destacados na subseção 2.1, os estudos anteriores dedicados à indústria de defesa, apesar de não se debruçarem sobre sistemas de controle de gestão adotados, prestam importantes contribuições à formação do conhecimento e à sistematização das características do setor. A temática "indústria de defesa" é abordada pelos pesquisadores das Ciências Econômicas e das Ciências Sociais, utilizando-se, preponderantemente, de pesquisa bibliográfica e documental. 
Processo de internacionalização das empresas brasileiras do segmento de segurança e defesa

Renato Santiago Quintal, Robson Augusto Dainez Condé, Leonardo Portugal Barcellos, Josir Simeone

Gomes

Trata-se de um assunto ainda pouco explorado pela academia, o que justifica a condução de pesquisas dessa natureza.

Matheus (2010) investigou de forma bastante peculiar a indústria de defesa brasileira, ao traçar uma análise da rede nacional a partir da teoria da dependência de recursos. O seu trabalho objetivou apresentar o estágio atual da estrutura produtiva de serviços e materiais de defesa. Seus principais achados contribuíram para a identificação dos fatores que mais impactaram a indústria de defesa brasileira.

O estudo de Dagnino e Campos Filho (2007) abordou a proposta de revitalização da indústria de defesa brasileira, por meio da cooperação entre nações sul-americanas e europeias. Por meio de uma revisão bibliográfica, os autores traçam um panorama dessa cooperação à luz de diversas variáveis, especialmente: atores envolvidos, mercados, capacidades produtivas e ameaças. Por fim, apontam a necessidade de uma melhor avaliação dos potenciais benefícios e dos reflexos da revitalização da indústria de defesa brasileira.

Dagnino (2008) estudou as contribuições da Economia de Defesa para as decisões sobre a revitalização da Indústria de Defesa Brasileira, concluindo que essa temática ingressou na recente pauta da política pública brasileira, mas que o país ainda carece de capacitação no assunto, quando comparado com outros países detentores de similar potencial tecnológico-produtivo. O cerne do estudo está voltado ao impacto econômico e tecnológico do gasto militar feito nos países desenvolvidos, bem como à maneira como aquelas potências vêm modificando seus marcos analítico-conceituais nas últimas décadas. Por último, o autor sugere que sua obra, alicerçada em uma pesquisa bibliográfica, sirva de subsídio ao processo de tomada de decisão no que tange à temática revitalização da Indústria de Defesa.

A pesquisa de Strachman e Degliesposti (2010) analisou o segmento industrial de carros de combate de pequeno porte com o objetivo de compreender o seu modo de operação. Para tal, os autores empreenderam um estudo de caso, amparado por pesquisa bibliográfica e documental, da empresa Engesa, maior fabricante brasileira de blindados no início da década de 1990. Os achados apontam para o fato de que o 
Processo de internacionalização das empresas brasileiras do segmento de segurança e defesa

Renato Santiago Quintal, Robson Augusto Dainez Condé, Leonardo Portugal Barcellos, Josir Simeone

Gomes

sucesso mundial da empresa ocorreu em função da percepção privilegiada de ocupação de um novo nicho de mercado associada à especial relação existente entre o seu Presidente e o Exército Brasileiro. Elucidam os principais fatores que contribuíram para falência da empresa na década de 1990 e, por último, identificam um potencial imenso de negócios que poderiam ser ocupados pela empresa ou por sucessora no mesmo ramo.

O trabalho de Júnior e Freire (2009) objetivou a compreensão e identificação das externalidades negativas geradas por seguidos orçamentos anuais destinados à Defesa Nacional, especialmente voltados à Força Aérea. Os principais achados dos autores apontam que os reduzidos aportes orçamentários e os sucessivos contingenciamentos no Orçamento de Defesa poderão fragilizar fluxos, processos e procedimentos orientados à viabilização do cumprimento dos dispositivos elencados na Constituição e na END. Adicionalmente, para aqueles autores, o círculo vicioso orçamentário conduz a prejuízos integrados e sinérgicos às Forças Armadas, à Defesa e ao Desenvolvimento Nacional, além de contribuir para a exposição da nação às frequentes ingerências externas em assuntos de natureza interna.

Avramesco e Cavali (2010) refletiram sobre a possibilidade de aperfeiçoamento dos procedimentos afetos à nacionalização de produtos na Base Industrial de Defesa, à luz da END. Por meio de pesquisa bibliográfica, apresentaram uma proposta de criação de um Centro de Nacionalização de Produtos de Defesa, no âmbito do Ministério da Defesa. Os achados apontam para a necessidade de modificações na estrutura organizacional daquele Ministério, com a finalidade da promoção da sinergia entre as três Forças, resultando em uma execução padronizada, ordenada e validada tecnicamente, orientada à nacionalização de artigos voltados ao segmento de defesa, preferencialmente detentores de independência tecnológica.

Racy e Silberfeld (2006) discutiram a importância da política de defesa como ferramenta da política nacional, especialmente no que se refere aos campos de reflexão das ciências econômicas e sociais. Como a grande maioria dos estudos na área, a pesquisa conduzida pelos autores adotou como metodologia a pesquisa bibliográfica e 
Processo de internacionalização das empresas brasileiras do segmento de segurança e defesa

Renato Santiago Quintal, Robson Augusto Dainez Condé, Leonardo Portugal Barcellos, Josir Simeone

Gomes

documental, que possibilitou aos pesquisadores constatarem a abordagem, ainda incipiente, com que o tema tem sido tratado recentemente. Os resultados apontam para a relevância assumida pelo tema no quadro atual das relações internacionais e na política interna brasileira, especialmente nas discussões sobre os rumos desenvolvimentistas e tecnológicos a serem seguidos e esforços direcionados pelo Estado à construção de um complexo industrial-militar expressivo.

O trabalho de Farias (2011) aborda o incentivo à indústria de defesa brasileira como política industrial e as implicações na política externa. Para tal, adota como recorte temporal o Governo do Presidente Lula, balizando-se em pesquisa bibliográfica. O autor aponta que o Brasil está tentando algo inédito: tornar-se uma potência mundial autônoma e não nuclear. Para enfrentar esse paradoxo, o autor recomenda que formuladores de políticas econômicas de defesa e externa conduzam com criatividade os assuntos dessa natureza.

Moreira (2010) discute, a partir de uma revisão bibliográfica, a atuação da Engenharia Militar ao longo do desenvolvimento científico e tecnológico estabelecido nas diretrizes da END. O pesquisador salienta que, a despeito do recente crescimento da importância geopolítica do Brasil no mundo, o país ainda persegue a capacitação tecnológica nos setores cibernético, aeroespacial e nuclear, conforme orientações contidas na END. Nesse aspecto, a Engenharia Militar tem assumido a proa do processo de consolidação da indústria de material de defesa nacional, não podendo ser olvidadas as seguintes contribuições: participação do Centro Tecnológico da Aeronáutica (CTA), Instituto Tecnológico da Aeronáutica (ITA) e Instituto Militar da Engenharia (IME) na criação da Empresa Brasileira de Aeronáutica (Embraer); fortalecimento da indústria e programa aeroespaciais; soerguimento da indústria de material bélico; programa nuclear da Marinha; Programa Antártico Brasileiro; e política brasileira de informática. Em última análise, Moreira (2010) discute o modelo de Engenharia Militar vislumbrado pelo país e os desafios que se descortinam.

Friede e Silva (2010) analisam a relevância da Lei n. 10.973, de 02 de dezembro de 2004, conhecida como Lei de Inovação Tecnológica, para a indústria nacional de 
Processo de internacionalização das empresas brasileiras do segmento de segurança e defesa

Renato Santiago Quintal, Robson Augusto Dainez Condé, Leonardo Portugal Barcellos, Josir Simeone

Gomes

defesa e, por conseguinte, para a consolidação da soberania do país. Os pesquisadores identificam que a problemática oriunda da dependência tecnológica brasileira foi a fonte de inspiração dos trabalhos legislativos que culminaram no Projeto de Lei n. 3.476/2004. Adicionalmente, avalizam que os liames da END estão em perfeita consonância com os dispositivos previstos na Lei de Inovação Tecnológica.

Mais especificamente no campo da gestão, o estudo de Pearce (1997) descreve e define cinco diferentes modelos de gestão aplicados aos principais estaleiros navais, abordando a importância da indústria naval para o interesse nacional. O pesquisador chileno analisa as indústrias navais do Hemisfério Norte - EUA, Grã-Bretanha, Alemanha, França e Espanha - e no Hemisfério Sul - Argentina, Brasil, Colômbia, Peru, Venezuela e Chile. Embora o estudo conclua que os estaleiros mundiais passam por uma crise, também evidencia que cada país tem problemas específicos, que requerem soluções diferenciadas, dependendo do país ou região, especialmente no que se refere ao ambiente político e às tendências econômicas de cada país. Nesse ambiente altamente competitivo, a solução encontrada pelos países do Hemisfério Norte tem sido a mudança do modelo de gestão e da promoção do trabalho cooperativo entre os estaleiros. Para os países da América do Sul, a solução foi individualizada para cada nação. Adicionalmente, Pearce (1997) examina a evolução gerencial de alguns dos principais estaleiros navais, especialmente a Chilean Shipbuilding and Docking Company.

A próxima seção aborda os procedimentos metodológicos empreendidos na pesquisa em lide.

\section{METODOLOGIA}

Esta seção é composta pelas seguintes subseções: seleção da amostra, coleta de dados e análise de dados. 
Processo de internacionalização das empresas brasileiras do segmento de segurança e defesa

Renato Santiago Quintal, Robson Augusto Dainez Condé, Leonardo Portugal Barcellos, Josir Simeone

Gomes

\subsection{Seleção da Amostra e Coleta de Dados}

O presente estudo é uma pesquisa descritiva, de natureza qualitativa e quantitativa. Para alcançar os objetivos propostos, foram selecionadas empresas filiadas à Associação Brasileira das Indústrias de Materiais de Defesa e Segurança (ABIMDE).

Os dados relativos a cada uma das empresas que compõem o setor foram cedidos pela Vice-Presidência Executiva e pela Diretoria Técnica da ABIMDE. De posse de informações, como endereço, telefone e correio eletrônico, encaminhou-se a cada um dos executivos das empresas do setor um questionário não estruturado constituído por 14 perguntas, estabelecendo-se um prazo de 12 dias para que houvesse 0 encaminhamento das respostas. Do total de 129 empresas, foram obtidas 19 respostas, $15 \%$ das filiadas à ABIMDE - 110 não se manifestaram, possivelmente motivadas por questões estratégicas.

Para Vieira et al. (2010), a taxa de retorno de questionários pode ser avaliada como satisfatória para pesquisas que utilizam esta metodologia, tornando a coleta de dados por meio de e-mail possivelmente adequada para ser empregada em pesquisas que envolvam o mesmo perfil do público escolhido para esse estudo, o que ocorreu na presente pesquisa, orientada a executivos de empresas filiadas à ABIMDE. Para Mattar (1996), a aplicação do questionário exerce uma menor pressão para obtenção de respostas; os respondentes dispõem de mais tempo para preencher as informações e vislumbra-se que tendam a fazê-lo com mais qualidade informacional.

\subsection{Análise dos Dados}

As informações contidas nos 19 questionários respondidos, após serem submetidas à análise de conteúdo, foram organizadas em forma de planilha eletrônica. Segundo Moraes (1999), a análise de conteúdo trata-se de um método voltado para a descrição e interpretação do conteúdo de quaisquer documentos e textos. Consiste de um exame minucioso calcado em descrições sistemáticas, de cunho qualitativo ou 
Processo de internacionalização das empresas brasileiras do segmento de segurança e defesa

Renato Santiago Quintal, Robson Augusto Dainez Condé, Leonardo Portugal Barcellos, Josir Simeone

quantitativo, que auxilia na reinterpretação das mensagens e no atingimento de um patamar de compreensão dos significados muito superior ao de uma leitura comum.

A partir da planilha supracitada, foram aplicados índices de frequências, para melhor compreender, em números, as ferramentas de controle de gestão mais utilizadas pelas empresas do setor estudado e elencadas na literatura em referência (ANTHONY; GOVINDARAJAN, 2002; MERCHANT, 1998; OTLEY, 1994; DYMENT, 1987).

\section{RESULTADOS}

Esta seção é composta pelas seguintes subseções: perfil das empresas respondentes; e sistemas de controle de gestão empregados.

\subsection{Perfil das Empresas Respondentes}

Nesta subseção, são apresentados aspectos preliminares relativos: (i) ao porte, (ii) à constituição do capital social (aberto ou fechado); (iii) ao nível de internacionalização; e (iv) à participação das receitas oriundas das atividades internacionalizadas sobre o total da Receita Operacional Bruta (ROB). Trata-se de análise descritiva, com a aplicação de medidas de frequência visando sistematizar as características das empresas respondentes.

O porte das empresas foi identificado a partir da aplicação da classificação adotada pelo Banco Nacional de Desenvolvimento Econômico e Social (BNDES), que considera o critério da receita operacional bruta anual $(R O B)$ para a categorização das empresas (BNDES, 2010). Observou-se que apenas uma empresa é classificada como média-grande empresa (Média-grande empresa: $R \$ 90$ milhões $>R O B$ anual $>R \$ 300$ milhões), sendo a única de capital aberto. Seis outras empresas estão classificadas como médias empresas (Média empresa: $R \$ 16$ milhões > ROB anual > R $\$ 90$ milhões) e nove como pequenas empresas (Pequena empresa: $R \$ 2,4$ milhões $>$ ROB anual $>$ $\mathrm{R} \$ 16$ milhões), representando juntas $80 \%$ das empresas estudadas. Por outro lado, 
três empresas enquadram-se no conceito de microempresa (Microempresa: ROB anual $<R \$ 2,4$ milhões). O Gráfico 1 ilustra a situação das empresas da amostra segundo essa classificação.

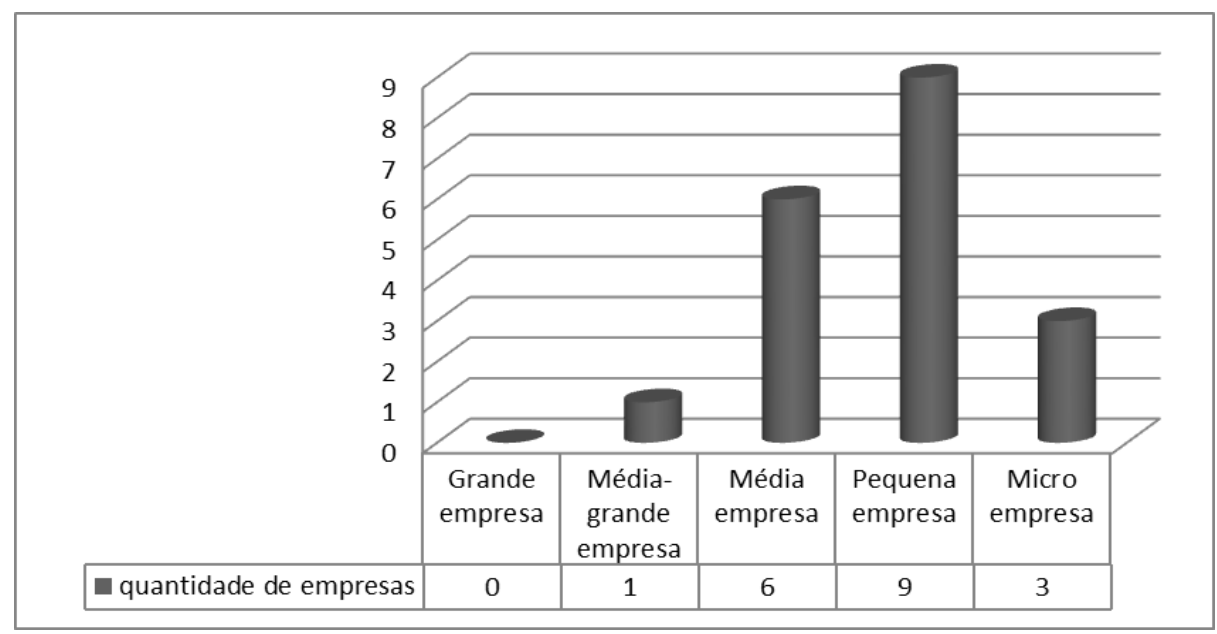

Gráfico 1 - Porte das empresas da amostra segundo classificação do BNDES

No que diz respeito à constituição do capital, conforme informado anteriormente, apenas uma entre as empresas amostradas é de capital aberto e mantém atividades com mercados estrangeiros, qualificando-se como empresa de capital aberto internacionalizada para os fins deste estudo. As outras 18 empresas são de capital fechado, resultado que se alinha àquele encontrado por Amaral et al. (2007), segundo os quais o cenário corporativo brasileiro, quando comparado ao das economias industriais avançadas, ainda é composto por um reduzido número de organizações de grande porte com atividades fora do país e apresenta significativo número de pequenas e médias empresas de capital fechado.

Em relação ao nível de internacionalização, foco deste estudo, constatou-se que, entre as empresas participantes, 10 mantêm negócios com o mercado externo, sendo que apenas uma possui subsidiárias de vendas no exterior, aspecto que revela um nível avançado de internacionalização, conforme Estágio 3 do modelo de Uppsala. Outras 9 empresas exportam por meio de representantes independentes, o que, de acordo com 
Processo de internacionalização das empresas brasileiras do segmento de segurança e defesa Renato Santiago Quintal, Robson Augusto Dainez Condé, Leonardo Portugal Barcellos, Josir Simeone

Dyment (1987), representa a primeira fase de internacionalização. O modelo de Uppsala reforça essa ideia de incipiência, classificando no Estágio 2 as empresas enquadradas nesse nível.

O uso de intermediadores consiste em uma forma indireta de realizar a exportação, que na maioria dos casos é realizada por trading companies ou por meio de importadores estrangeiros baseados no país de onde provém a exportação. Assim, além do reduzido aporte de investimentos e da baixa exposição a riscos, o exportador exerce pouca ingerência sobre a comercialização da sua mercadoria, já que essa etapa está a cargo de agentes externos (LAZZARI et al., 2009).

O último aspecto preliminar investigado foi a participação das receitas oriundas das operações com o exterior no total de receitas apurado pelas empresas respondentes. A distribuição de frequência é demonstrada na Tabela 1.

Tabela 1 - Participação das receitas oriundas das atividades internacionalizadas

\begin{tabular}{c|c}
\hline $\begin{array}{c}\text { Participação das receitas oriundas de } \\
\text { atividades internacionalizadas na ROB }\end{array}$ & $\begin{array}{c}\text { Quantidade de } \\
\text { empresas } \\
\text { internacionalizadas }\end{array}$ \\
\hline Até $10 \%$ & 4 \\
\hline $10 \%$ a $20 \%$ & 1 \\
\hline $20 \%$ a $30 \%$ & 1 \\
\hline $30 \%$ a $40 \%$ & 2 \\
\hline $40 \%$ a $50 \%$ & 2 \\
\hline Acima de $50 \%$ & 0 \\
\hline TOTAL & $\mathbf{1 0}$ \\
\hline
\end{tabular}

Os resultados corroboram os dados referentes ao nível de internacionalização identificado - a maior parte das empresas não ultrapassou a marca de $30 \%$ de receitas oriundas de atividades no exterior, sendo que 4 delas teve participação inferior a 10\%.

\subsection{Sistemas de Controle de Gestão empregados}

Esta subseção aborda as características dos sistemas de controle gerencial das empresas estudadas, notadamente em relação: (i) às ferramentas de controle 
Processo de internacionalização das empresas brasileiras do segmento de segurança e defesa

Renato Santiago Quintal, Robson Augusto Dainez Condé, Leonardo Portugal Barcellos, Josir Simeone

Gomes

empregadas; (ii) à divisão da organização em centros de responsabilidade; (iii) à utilização de formas de remuneração por desempenho; e (iv) à estratégia competitiva da empresa. Como na subseção anterior, utilizou-se uma análise descritiva, objetivando sistematizar as características dos sistemas de controle gerencial das empresas.

Ao investigar os indicadores de controle utilizados, o questionário buscou capturar as principais ferramentas de controle empregadas pelas 19 empresas em estudo. Pode-se constatar, conforme gráfico 2, que as opções variaram bastante. As ferramentas mais utilizadas pelas empresas foram o lucro antes de juros, impostos, depreciação e amortização (EBITDA), o Benchmarking e o Orçamento, denotando a importância desses indicadores, principalmente o orçamento por ser a ferramenta mais utilizada pelas empresas.

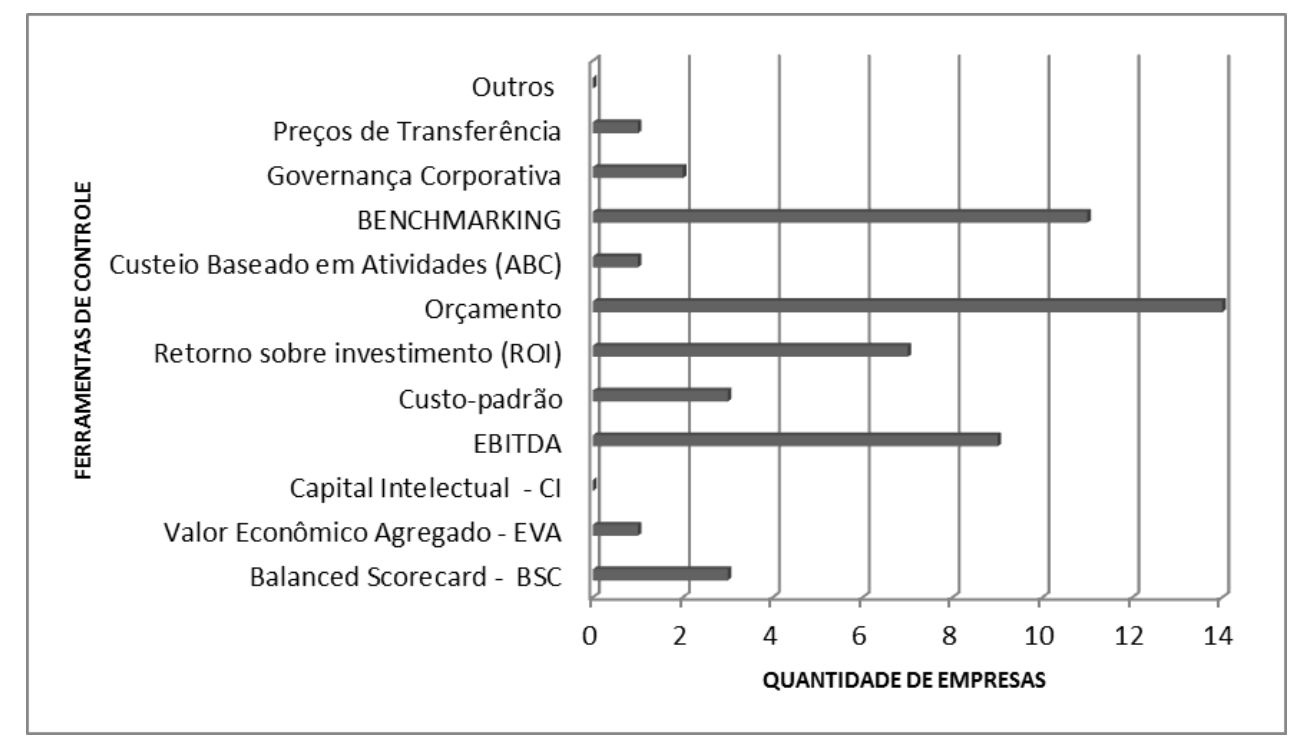

Gráfico 2 - Ferramentas de controle gerencial utilizadas pelas empresas investigadas

Ao considerar na análise, apenas as 10 empresas internacionalizadas, se observa que o EBITDA, o Benchmarking e o Orçamento continuam sendo as ferramentas mais utilizadas; entretanto, vale ressaltar que para as empresas internacionalizadas o Benchmarking passa a ser a ferramenta de controle mais 
Processo de internacionalização das empresas brasileiras do segmento de segurança e defesa

Renato Santiago Quintal, Robson Augusto Dainez Condé, Leonardo Portugal Barcellos, Josir Simeone

Gomes

utilizada, demonstrando a preocupação destas empresas em adotar as melhores ferramentas de controle de gestão disponíveis no mercado e aderentes à literatura supracitada.

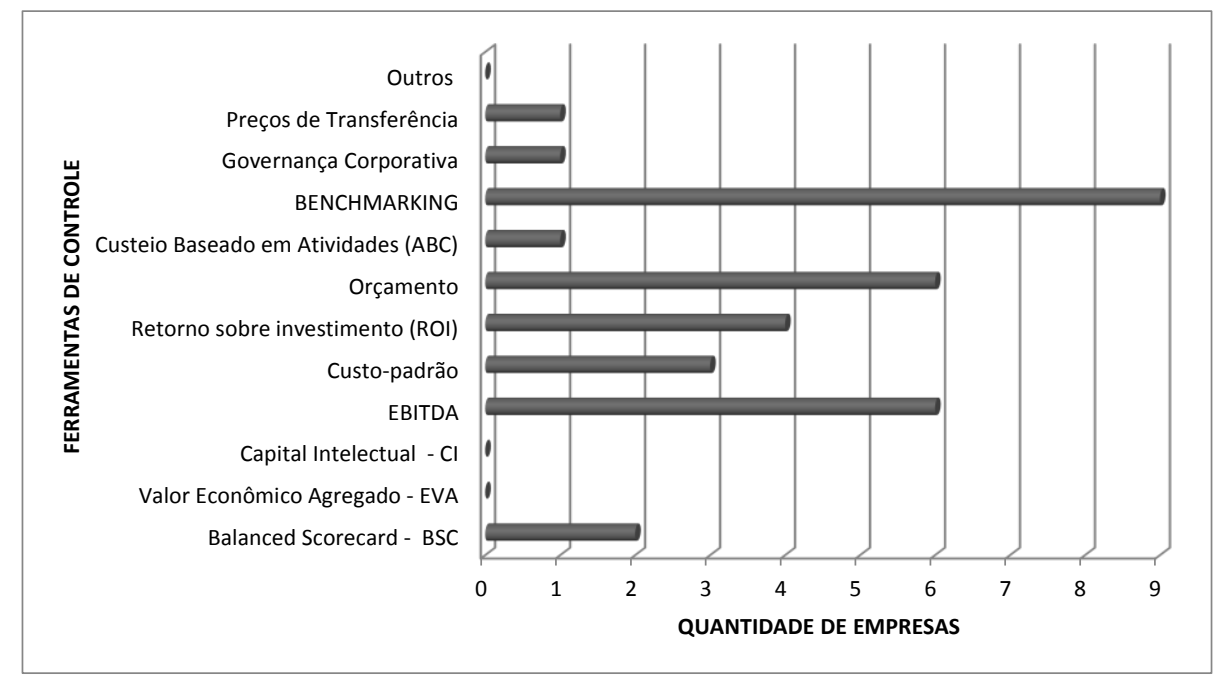

Gráfico 3 - Ferramentas de controle gerencial utilizadas pelas empresas internacionalizadas

Analisando o aspecto organizacional, observou-se que $90 \%$ das empresas internacionalizadas estão divididas em centros de responsabilidade financeira, sendo o centro de custos ou despesas o mais importante centro de responsabilidade da organização. Quando observadas as empresas não internacionalizadas, este percentual cai significativamente para $33 \%$, indicando que a decisão de ampliar as atividades da empresa para o exterior deve estar acompanhada do estudo de possíveis alterações na estrutura organizacional de suas unidades.

Quanto ao método utilizado para remunerar seu pessoal, constatou-se que, entre as empresas internacionalizadas, $80 \%$ utilizam alguma forma de bonificação para seus funcionários, com base no cumprimento de metas estabelecidas pela empresa, sejam eles do nível operacional, gerencial ou de direção da empresa. Por outro lado, entre as empresas não internacionalizadas, apenas 33\% adotam esta forma de remuneração. Estes resultados, embora não possam ser generalizados, estão alinhados ao preconizado por Dyment (1987), segundo o qual um gerente deve ser remunerado de 
Processo de internacionalização das empresas brasileiras do segmento de segurança e defesa

Renato Santiago Quintal, Robson Augusto Dainez Condé, Leonardo Portugal Barcellos, Josir Simeone

Gomes

um salário base, incentivos, participação nos lucros e um prêmio baseado no cumprimento de metas importantes para a empresa.

Outro aspecto abordado nesta subseção foi a estratégia competitiva da empresa. Segundo Dyment (1987), existem duas estratégias para se conseguir uma vantagem competitiva: custo e diferencial do produto. Segundo Porter (1980), a estratégia de liderança de custo importa na obtenção de vantagens competitivas pelo oferecimento de produtos e serviços a um custo mais reduzido, enquanto a diferenciação implica no alcance de vantagens pelo acréscimo de um ou mais componentes de diferenciação nos produtos e serviços, que respaldem a prática de preços mais elevados. Exemplificando o uso destas estratégias, Dyment (1987) menciona que a Toyota obteve grande vantagem competitiva sobre as montadoras Chevrolet e Rolls-Royce, utilizando conjuntamente as duas estratégias.

Os respondentes das empresas da amostra foram questionados sobre o seu foco estratégico competitivo. Os resultados indicam que todas as empresas que mantêm ou não negócios com o exterior adotam, em níveis bem aproximados, ambas as estratégias, embora utilizem a estratégia de diferenciação de forma mais significativa que a redução de custos. Esses achados podem ser considerados previsíveis, pois, com a homogeneização da demanda mundial, a adoção de técnicas de padronização da produção tem possibilitado a redução de custos das empresas e, ao mesmo tempo, a melhoria na qualidade de seus produtos.

Desta forma, convergindo com o previsto na literatura (ANTHONY; GOVINDARAJAN, 2002; MERCHANT, 1998; DYMENT, 1987; GOMES; SALAS, 2001; MACIARIELLO; KIRBY, 1994), a decisão das empresas desse segmento de expandir suas atividades, além das fronteiras do país de origem, pode provocar significativas mudanças na sua estrutura organizacional e nos seus sistemas de controle de gestão. 
Processo de internacionalização das empresas brasileiras do segmento de segurança e defesa

Renato Santiago Quintal, Robson Augusto Dainez Condé, Leonardo Portugal Barcellos, Josir Simeone

Gomes

\section{CONSIDERAÇÕES FINAIS}

O presente estudo teve por objetivo investigar o processo de internacionalização das empresas que compõem o segmento de segurança e defesa, bem como analisar os impactos decorrentes desse processo em seus sistemas de controle de gestão. A coleta de dados foi feita por meio de um questionário não estruturado, submetido a todas as 129 empresas filiadas a ABIMDE, sendo que 15\% delas responderam.

Em linhas gerais, os resultados e contribuições deste estudo podem ser assim sintetizados: das 10 empresas internacionalizadas, uma possui subsidiária de vendas no exterior e as demais exportam por meio de representantes independentes; as principais ferramentas de gestão utilizadas nas empresas são EBITDA, Orçamento e Benchmarking, sendo esta última a mais utilizada; nove estão divididas em centros de responsabilidade financeira, sendo o centro de custos ou despesas o mais importante centro de responsabilidade da organização; em sua maioria, utilizam o sistema de remuneração por bonificação pelo cumprimento de metas e adotam, em níveis bem aproximados, as estratégias de diferenciação do produto e de redução de custos, simultaneamente.

Quanto aos impactos do processo de internacionalização, podem ser percebidas modificações na estrutura organizacional e no controle de gestão das empresas, que se apresentaram bem diferentes no Brasil e no exterior nos seguintes aspectos: i) quanto à forma de remuneração do pessoal, as empresas, uma vez internacionalizadas, passaram a remunerar seus funcionários, com base no cumprimento de metas estabelecidas pela empresa; ii) quanto à ferramenta de controle de gestão utilizada, o Benchmarking despontou como a mais importante para as empresas internacionalizadas, demonstrando a preocupação dessas empresas em adotar as melhores práticas do mercado; por outro lado, para as empresas que não praticam atividades no exterior, o Orçamento se constituiu na principal ferramenta; iii) no que se refere ao aspecto organizacional, as empresas que optaram pela internacionalização passaram a se organizar em centros de responsabilidade financeira, evidenciando que 
Processo de internacionalização das empresas brasileiras do segmento de segurança e defesa

Renato Santiago Quintal, Robson Augusto Dainez Condé, Leonardo Portugal Barcellos, Josir Simeone

a decisão de ampliar os negócios para o exterior requer análise sobre possíveis alterações na estrutura organizacional de suas unidades.

Desta forma, convergindo com o previsto na literatura (ANTHONY; GOVINDARAJAN, 2002; MERCHANT, 1998; DYMENT, 1987; GOMES; SALAS, 2001; MACIARIELLO; KIRBY, 1994), a decisão das empresas desse segmento de expandir suas atividades, além das fronteiras do país de origem, pode provocar significativas mudanças na sua estrutura organizacional e nos seus sistemas de controle de gestão.

Como toda pesquisa, este estudo possui limitações. O resultado da pesquisa está restrito aos aspectos revelados nos questionários respondidos, impossibilitando a sua generalização para outras empresas, ainda que do mesmo segmento. Por fim, apesar das dificuldades em se obter informações sobre os sistemas de controle gerencial das empresas, recomendam-se, para pesquisas futuras, estudos de mesma natureza que possam corroborar os resultados aqui apresentados, bem como a realização de pesquisas que abordem outros aspectos das empresas do setor da indústria de defesa.

\section{AGRADECIMENTOS}

Os autores agradecem à Vice-Presidência Executiva e à Diretoria-Técnica da $A B I M D E$, bem como às empresas associadas pela contribuição dada à pesquisa.

\section{REFERÊNCIAS}

AGÊNCIA BRASILEIRA DE DESENVOLVIMENTO INDUSTRIAL - ABDI. (2011). Diagnóstico: Base Industrial de Defesa Brasileira. Campinas - SP. Disponível em: http://www.abdi.com.br/Estudo/relatorio_neit_04-defesa_01b.indd.pdf. Acesso em: 12/nov/2011.

AMARAL, H. F; MOREIRA, B.C.M; GRUBERGER, D.J; IQUIAPAZA, R.A. (2007). Qualidade da Governança Corporativa das empresas na BOVESPA e internacionalização: Evolução 2002-2005. In: CONGRESSO DO INSTITUTO FRANCOBRASILEIRO DE ADMINISTRAÇÃO DE EMPRESAS - IFBAE, IV, 2007, Porto Alegre RS. Anais. 
Processo de internacionalização das empresas brasileiras do segmento de segurança e defesa

Renato Santiago Quintal, Robson Augusto Dainez Condé, Leonardo Portugal Barcellos, Josir Simeone

Gomes

ANTHONY, R. N; GOVINDARAJAN, V. (2002). Sistemas de controle gerencial. São Paulo: Atlas, $1019 \mathrm{p}$.

ASSOCIAÇÃO BRASILEIRA DAS INDÚSTRIAS DE MATERIAIS DE DEFESA E SEGURANÇA - ABIMDE. Estatuto Social da ABIMDE. Disponível em: http://www.abimde.org.br/?on=abimde\&in=estatutos. Acesso em: 12/nov/2011.

ASSOCIAÇÃO BRASILEIRA DAS INDÚSTRIAS DE MATERIAIS DE DEFESA E SEGURANÇA (ABIMDE). (2008). In: SEMINÁRIO DE CIÊNCIA E TECNOLOGIA DE INTERESSE DA DEFESA NACIONAL, Rio de Janeiro, RJ. Anais. Disponível em: https://www.defesa.gov.br/ciencia_tecnologia/index.php?page=vi_seminario2008.

Acesso em: 12/nov/2011.

AVRAMESCO, R. L; CAVALI, S. G. M. (2010). Produtos de Defesa: um centro de nacionalização. Revista da Universidade da Força Aérea, Rio de Janeiro, v. 23, p.79-90.

BANCO NACIONAL DO DESENVOLVIMENTO ECONÔMICO E SOCIAL - BNDES. Circular n. 11, de 5 de março de 2010. Disponível em: http://www.bndes.gov.br/SiteBNDES/export/sites/default/bndes_pt/Galerias/Arquivos/pro dutos/download/Circ011_10.pdf. Acesso em: 12/nov/2011.

BARTLETT, C. A; GHOSHAL, S. (1992). Gerenciando empresas no exterior: a solução transnacional. São Paulo: Makron Books.

BASTOS, E. C. S. (2008). Indústria de Defesa no Brasil: algumas reflexões. Revista do Clube Militar, Rio de Janeiro, n. 429, p.10-11.

BRASIL. Decreto n. 6.703, de 18 de dezembro de 2008. Aprova a Estratégia Nacional de Defesa. Disponível em: http://www.planalto.gov.br/ccivil_03/_Ato20072010/2008/Decreto/D6703.htm. Acesso em: 07/set/2011.

BRASIL. Ministério da Defesa. Portaria n. 899, de 19 de julho de 2005. Aprova a Política Nacional da Indústria de Defesa. Disponível em: https://www.defesa.gov.br/sistemas/bdlegis/dados_norma.php?numero=899\&ano=2005 \&serie $=$ A Acesso em: 29/dez/2011.

BRASIL, F. L; ORTEGA, L. M. (2006). Análise de Estratégia de Internacionalização - o Caso Bematech. In: WORKSHOP SOBRE INTERNACIONALIZAÇÃO DE EMPRESAS, 2006, São Paulo. FEA-USP, Anais.

CANALS, J. (1994). La internacionalizacion de la empresa. Madrid: McGraw-Hill. 
Processo de internacionalização das empresas brasileiras do segmento de segurança e defesa Renato Santiago Quintal, Robson Augusto Dainez Condé, Leonardo Portugal Barcellos, Josir Simeone

CONCA, K. Technology, the military, and democracy in Brazil. (1992). Journal of Interamerican Studies and World Affairs, Miami, v. 34, n. 1, p.141-177.

CONDÉ, R.A.D; QUINTAL, R.S; BARCELLOS, L.P; GOMES, J.S. (2011). Os desafios administrativos na adoção de sistemas de controle para empresas globalizadas. In: ENCONTRO DO PPG EM CIÉNCIAS CONTÁBEIS DA UNISINOS, II, 2011, São Leopoldo. Anais.

CUNHA, M. B. (2005). Indústria brasileira de material de defesa. Revista do Clube Naval, Rio de Janeiro.

DAGNINO, R. P. (2008). Em que a Economia de Defesa pode ajudar nas decisões sobre a revitalização da Indústria de Defesa brasileira? Revista Oikos, Rio de Janeiro, v. 1, p. 113-137.

DAGNINO, R. P; CAMPOS FILHO, L. A. N. (2007). A revitalização da Indústria de Defesa Brasileira: Análise da alternativa Cooperação Sul-americano Européia. Vértices, Campos dos Goitacazes, v. 9, n. 1/3, p. 25-34.

DELLAGNEZZE, R. (2008). 200 anos da indústria de defesa no Brasil. Revista Âmbito Jurídico, Rio Grande, v. 52. Disponível em: http://www.ambitojuridico.com.br/site/index.php?n_link=revista_artigos_leitura\&artigo_id=2652.Acesso em 07 set. 2011.

DYMENT, J. J. (1987). Strategies and management controls for global corporations. The journal of business strategy, Boston, v.7, n.4, p.20-26.

FARIAS, A. J. (2011). O incentivo à indústria de defesa como política industrial: uma apreciação das iniciativas do governo Lula e suas implicações para a política internacional. In: ALVES, V. C; MOREIRA, W. de S; ARIAS NETO, J. M. (Org). A Defesa e a Segurança na América do Sul: IV Encontro da ABED. Campinas: Mercado de Letras.

FERNANDES NETO, A. F. (2006). A importância da globalização para as empresas brasileiras. Thesis, São Paulo, v. 5, p. 1-20.

FLORENTINO, M. S; GOMES, J. S. (2009). Controle gerencial em empresas brasileiras internacionalizadas: empresas do setor de serviços - o caso da SPOLETO. Revista Contabilidade Gestão e Governança, Brasília, v. 12, n. 2, p. 24-34.

FRANKO-JONES, P. (1988). Public private partnership: lessons from the Brazilian armaments industry. Journal of Interamerican Studies and World Affairs, Miami, v. 29, n. 4. p. 41-68. 
Processo de internacionalização das empresas brasileiras do segmento de segurança e defesa

Renato Santiago Quintal, Robson Augusto Dainez Condé, Leonardo Portugal Barcellos, Josir Simeone

Gomes

FRIEDE, R.; SILVA, A. C. (2010). A Lei de Inovação Tecnológica e sua importância para a recuperação da indústria nacional de defesa e para a manutenção da soberania nacional. Revista do Clube Naval, Rio de Janeiro, v. 353, p. 42-47.

GOMES, J. S; OLIVEIRA, R. R. (2011). Inserção do tema internacionalização de empresas em artigos produzidos no Programa de Mestrado em Ciências Contábeis da UERJ. In: CONGRESSO NACIONAL DE EXCELÊNCIA EM GESTÃO - CNEG, VII, 2011, Niterói. Anais.

GOMES, J. S; RODRIGUES, A. (2005). Um estudo exploratório sobre controle gerencial em empresas brasileiras internacionalizadas do setor de serviços: quatro estudos de casos. In: ENCONTRO ANUAL DA ANPAD, XXIX, 2005, Brasília. Anais.

GOMES, J. S; SALAS, J. M. A. (2001). Controle de gestão: uma abordagem contextual e organizacional. (3 ed.). São Paulo: Atlas, 192 p.

JÚNIOR, A.F.S; FREIRE, L. T. (2009). Orçamento e contingenciamentos: potencialização dos impactos negativos e fragilização da defesa nacional. In: SIMPÓSIO DE EXCELÊNCIA EM GESTÃO E TECNOLOGIA, VIII, 2009, Resende. Anais.

LAZZARI, F; VERRUCK, F; BAMPI, R.E; DORION, E; GOLÇALVES, R.B. (2009). Internacionalização em empresas de médio porte: um estudo multicaso na Serra Gaúcha. In: SEMEAD - Seminários em Administração, XII, 2009, São Paulo. Anais.

LONGO, W. P. (2007). Tecnologia militar: conceituação, importância e cerceamento. Tensões Mundiais, Fortaleza, v. 3, n. 5, p. 111-143.

MACIARIELLO, J. A; KIRBY, C. J. (1994). Management control systems: using adaptive systems to attain control. (2nd). Upper Saddle River: Prentice Hall.

MATHEUS, A. S. (2010). Indústria de defesa: uma análise da rede nacional a partir da teoria da dependência de recursos. 2010. 120 f. (Dissertação de Mestrado). Fundação Getúlio Vargas, Escola Brasileira de Administração Pública e de Empresas (EBAPE), Rio de Janeiro.

MATTAR, F. N. (1996). Pesquisa de Marketing: metodologia e planejamento. São Paulo: Editora Atlas, $336 \mathrm{p}$.

MERCHANT, K. (1998). Modern management control systems: text \& cases. Upper Saddle River: Prentice Hall. 
Processo de internacionalização das empresas brasileiras do segmento de segurança e defesa

Renato Santiago Quintal, Robson Augusto Dainez Condé, Leonardo Portugal Barcellos, Josir Simeone

MORAES, R. (1999). Análise de conteúdo. Revista Educação, Porto Alegre, v. 22, n. 37, p. 7-32.

MOREIRA, L. G. G. (2010). C\&T e Indústria de Defesa: o papel da Engenharia Militar no desenvolvimento nacional autônomo. In: ENCONTRO NACIONAL DA ASSOCIAÇÃO BRASILEIRA DE ESTUDOS DE DEFESA, IV, Brasília, 2010. Anais.

OTLEY, D. (1994). Management control in contemporary organizations: towards a wider framework. Management Accounting Research, n.5, p. 289-299.

PEARCE, H.J. (1997). The Future of the Chilean Shipbuilding and Docking CompanyASMAR: A Strategic Management Model Analysis. Monterey, California. Dissertation. Naval Postgraduate School, $151 \mathrm{p}$.

PORTER, M. E. (1980). Competitive strategy. New York: The Free Press.

PROENÇA JR., D; DINIZ, E. (1998). Política de defesa no Brasil: uma análise crítica. Brasília: Universidade de Brasília.

RACY, J. C; SILBERFELD, J. C. E. (2006). Defesa Nacional, complexo industrial-militar e mobilização industrial: apontamentos para a mobilização nacional. Revista de Economia Mackenzie, São Paulo.

ROCHA, A. (2004). O constructo da distância psicológica: componentes, mediadores e assimetria. In: HEMAIS, C. A. (Org). O Desafio dos Mercados Externos: teoria e prática na internacionalização da firma. v. 1. Rio de Janeiro: Mauad.

SCHWAM-BAIRD, D. M. (1997). Military ideologies in the making of Brazil's arms industry. Maryland: University Press of American Inc.

SOTTO MAYOR FILHO, L. A; FERREIRA, G. C. (2006). Internacionalização de empresas de prestação de serviços em tecnologia de informação: o estudo de caso de duas empresas brasileiras. In: ENCONTRO ANUAL DA ANPAD, XXX, 2006, Salvador. Anais.

STRACHMAN, E; DEGLIESPOSTI, E. H. B. (2010). A Indústria de Defesa Brasileira: o setor de carros de combate e a Engesa. Revista Ensaios FEE (Impresso), Porto Alegre, v. 31, p. 31-58.

TEIXEIRA, A. G. (2006). A internacionalização de empresas brasileiras e o papel do Estado. In: FÓRUM NACIONAL. Estudos e Pesquisas, Rio de Janeiro, XVIII, n. 160. Disponível em: www.forumnacional.org.br/trf_arq.php?cod=EP01600. Acesso em: 25/nov/2011. 
Processo de internacionalização das empresas brasileiras do segmento de segurança e defesa Renato Santiago Quintal, Robson Augusto Dainez Condé, Leonardo Portugal Barcellos, Josir Simeone

Gomes

VIEIRA, H.C.; CASTRO, A.E. e JÚNIOR SCHUCH, V.F. (2010). O uso de questionários via e-mail em pesquisas acadêmicas sob a ótica dos respondentes. XIII SEMEAD. Seminários em administração. São Paulo. Anais. Disponível em: http://www.ead.fea.usp.br/semead/13semead/resultado/trabalhosPDF/612.pdf. Acesso em 18/jun/2014.

Data de Submissão: 31/10/2012

Data de Aceite: 25/04/2014 